\title{
Diyabetik Bir Hastada Venöz Yetersizlik ile Karışan Charcot Nöroartropatisi
}

\author{
Charcot Neuroarthropathy Confused with Venous Insufficiency in a Diabetic Patient
}

\author{
Rabia Terzi, Tülay Özer*, Turgay Altınbilek** \\ Derince Eğitim ve Araştırma Hastanesi, Fiziksel Tıp ve Rehabilitasyon Kliniği, Kocaeli, Türkiye \\ *Derince Eğitim ve Araştırma Hastanesi, Radyoloji Kliniği, Kocaeli, Türkiye \\ **Haliç Üniversitesi Sağlık Bilimleri Yüksekokulu, Fizyoterapi ve Rehabilitasyon Bölümü, İstanbul, Türkiye
}

\section{Öz}

Charcot nöroartropatisi (CN) başta diyabet olmak üzere duysal ve otonom nöropati yapan tüm hastalıklarda görülebilen, genellikle ayak ve ayak bileğinin etkilendiği progresif seyirli bir hastalıktır. Özellikle diyabet seyrinde görülen enfeksiyonlar ve vasküler patolojiler başta olmak üzere birçok klinik antite ile karışabildiğinden tanıda gecikmeler yaşanmaktadır. Bu olgu sunumunda; 59 yaşında sağ ayakta şişlik ve ağıı yakınması ile başvuran ve daha öncesinde venöz yetersizlik tanısı almış diyabetik bir hastada, CN tespit edilmiş ve literatür eşliğinde sunulmuştur.

Anahtar kelimeler: Charcot nöroartropatisi, diabetes mellitus, duysal nöropati, otonom nöropati, ayak

\section{Abstract}

Charcot neuroarthropathy $(\mathrm{CN})$ is a disease with a progressive course which usually affects the foot and ankle and can be seen with all the diseases causing sensory or autonomic neuropathy, primarily diabetes. Diagnosis can be delayed since it may be confused with many clinical entities, particularly infections and vascular pathologies which are seen especially in the course of diabetes. In this case report a 59 year-old diabetic patient, who presented with swelling and pain in the right foot, was previously diagnosed with venous insufficiency and then found to have $\mathrm{CN}$, was presented together with a literature review.

Keywords: Charcot neuroarthropathy, diabetes mellitus, sensory neuropathy, autonomic neuropathy, foot

\section{Giriș}

Charcot nöroartropatisi (CN) nadir görülen, genellikle ayak ve ayak bileğinin etkilendiği, osteoligamantöz mimarisinde bozulma ile karakterize nonenfeksiyöz progresif seyirli bir hastalıktır (1-3). illk kez 1868 yılında Jean Martin Charcot tarafından tarif edilmiştir (4). Duysal ve otonom nöropati yapan tüm hastalıklarda görülebilir. En sık diyabet ile birlikteliği gösterilmiştir. Kronik alkolizm, sifiliz, lepra, siringomyeli, kurşun intoksikasyonu, poliomiyelit, spinal kord yaralanmaları, multipl skleroz, romatoid artrit, ayak cerrahisi ve renal transplant sonrası gelişebileceği diğer durumlar olarak bildirilmiştir (5). En sık ayak ve ayak bileğinde görülmesine rağmen, el bileği, omuz, omurga ve dizde görülebildiği bildirilmiştir (3).

CN diyabetik hastaların \%0,8-8'ini etkilemektedir. Diyabetik hastalarda enfeksiyon ve vasküler patolojilerin sık görülmesi ve klinik bulgularının CN ile benzerliği tanı karmaşasına neden olabilmekte ve tanıda gecikmeler yaşanmaktadır $(2,6)$. Wukich ve ark. (7) bu hastalarda tanının 8 hafta kadar geciktiği, bu nedenle bu hastalarda progresyon ve komplikasyonların sık görüldüğünü bildirmişlerdir. Bu olgu sunumunda sağ ayak ve ayak bileğinde şişlik ve ağrı yakınması ile başvuran ve öncesinde venöz yetersizlik tanısı almış bir hastada CN saptanmış ve literatür eşliğinde sunulmuştur.

\section{Olgu Sunumu}

Elli dokuz yaşında kadın hasta, sağ ayakta yaklaşık 3 aydır var olan şişlik ve uzun süreli ayakta kalma ile atış gösteren ayak ağrısı yakınması ile kliniğimize başvurdu. Özgeçmişinde yaklaşık 13 yıldır diyabet ve hipertansiyon tanısı olduğu ve insülin ve antihipertansif tedavi aldığını belirtti. Üç yıl önce diyabetik sensöriomotor polinöropati tanısı aldığı ve pregabalin 150 mgx2 kullandığını bildirdi. Sağ bacakta şişlik yakınmasıyla kalp damar cerrahisi kliniğine başvurduğu, yapılan alt ekstremite venöz Doppler ultrasonografisinde yüzeyel venöz yetersizlik

Yazışma Adresi/Address for Correspondence: Dr. Rabia Terzi, Derince Eğitim ve Araştırma Hastanesi, Fiziksel Tıp ve Rehabilitasyon Kliniği, Kocaeli, Türkiye Tel.: +90 5053515572 E-posta: drrabia1@yahoo.com Geliş Tarihi/Received: 16.10.2015 Kabul Tarihi/Accepted: 08.12.2015 
tespit edilerek, medikal tedavi verildiği öğrenildi. Şikayetlerinin devam etmesi üzerine kliniğimize başvuran hastada herhangi bir travma öyküsü bulunmamaktaydı. Fizik muayenesinde sağ ayak ayak bileği ve pretibial bölgede ödem ve çap artışı izlendi (Resim 1). Ayak bileği eklem hareketi açık ve internal rotasyonda minimal ağrısı mevcuttu. Diyabetik ülser izlenmedi. Ayak kavsinde minimal kısalma mevcuttu. Her iki alt ekstremitede diz ekleminin distalinde çorap tarzında duyu kusuru mevcuttu. Kas gücü muayenesi olağandı. Aşil ve patella refleksleri bilateral hipoaktifti. Periferik nabızları açıktı. Hastanın laboratuvar tetkiklerinde eritrosit sedimentasyon hız 25 mm/saat, C-reaktif protein negatif, hemogram normal, açlık kan şekeri $152 \mathrm{mg} /$ $\mathrm{dL}$, hemoglobin A1c \%9,7; üre $32 \mathrm{mg} / \mathrm{dL}$, kreatinin 0,85 mg/ $\mathrm{dL}$, aspartat aminotransferaz $12 \mathrm{U} / \mathrm{L}$, alanin aminotransferaz $16 \mathrm{U} / \mathrm{L}$, ürik asit $4,5 \mathrm{mg} / \mathrm{dL}$ olarak tespit edildi. Sağ ayak anteroposterior ve lateral $\mathrm{X}$ ray grafilerinde, talonavikular ve navikuloküneiform eklemler ile tarso-metatarsal eklemlerde eklem aralığının kaybı ile birlikte belirgin dejenerasyon izlendi. Naviküler kemikte fragmantasyon ve kollaps mevcuttu. Ayak lateralinde 5. metatarsal kemik proksimalinde ve kuboid kemik komşuluğunda kemik fragmanları mevcuttu (Resim 1). Sağ ayağın manyetik rezonans görüntülemede (MRG) incelemesinde talonavikülar, naviküloküneiform, kalkaneoküboid eklemler ile tarso-metatarsal eklemlerde periartiküler kemik iliği ödemi, disorganizasyon ve yumuşak doku kolleksiyonları izlendi. Kontrastlı serilerde periartiküler yumuşak dokuda ve subkortikal eklem yüzeylerinde zayıf kontrast tutulumları izlendi (Resim 2). Hastanın arteriyel Doppler ultrasonografisinde oklüzyon ya da stenoz bulguları saptanmadı. Venöz Doppler ultrasonografisinde sınıf 2 yüzeyel venöz yetersizliği mevcuttu. Hastaya mevcut klinik ve radyolojik bulgular ile venöz yetersizlik ve CN tanısı konuldu. Kalp damar cerrahisi 500 mg flavonoid 2x1 önerdi. CN açısından ortopedi ile konsülte edilen hastaya cerrahi düşünülmedi. Hastaya, yüklenmenin azaltılması ve ortez kullanımı önerilerek takibe alındı.
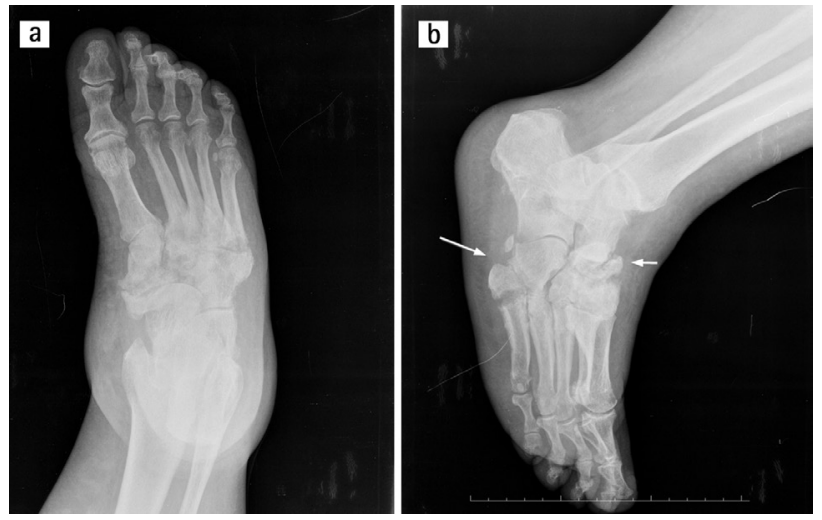

Resim 1. Sağ ayak anteroposterior (a) ve lateral (b) $X$ ray grafilerinde, talonavikülar ve naviküloküneiform eklemler ile tarso-metatarsal eklemlerde eklem aralığının kaybı ile birlikte belirgin dejenerasyon, naviküler kemikte fragmantasyon ve kollabs (kısa ok) izleniyor. Ayak lateralinde 5. metatarsal kemik proksimalinde ve kuboid kemik komşuluğunda kemik fragmanları (uzun ok) görülüyor
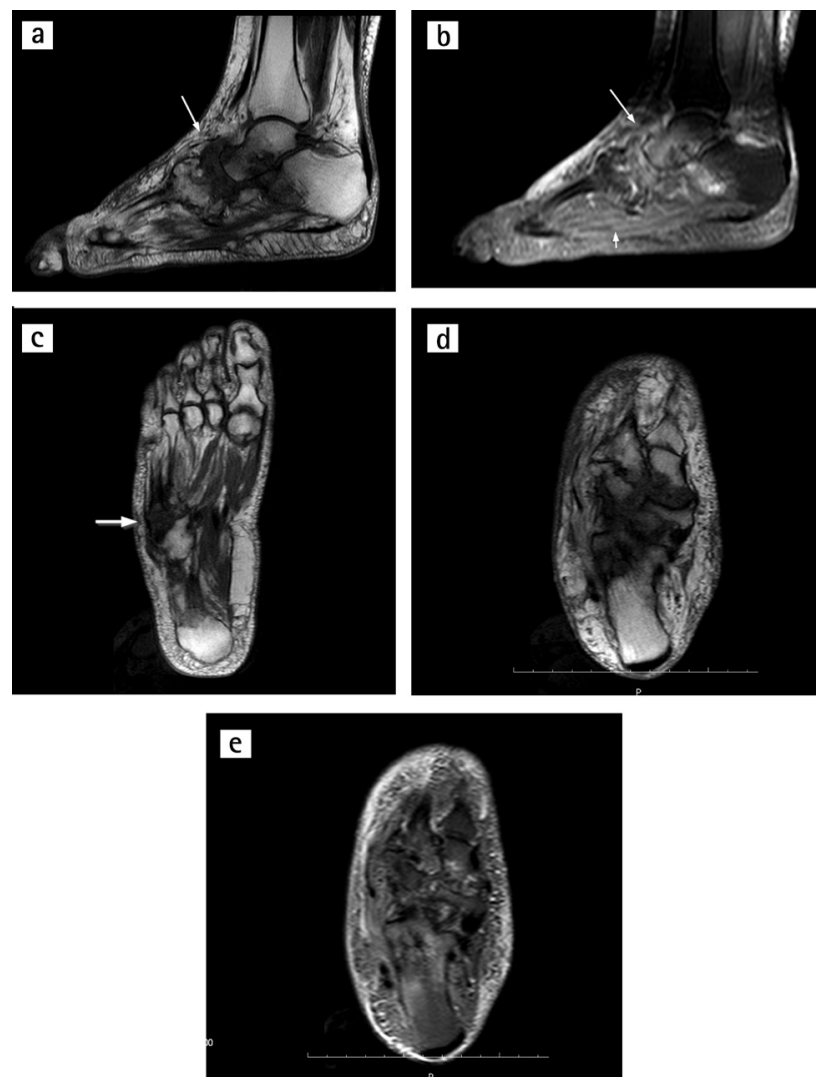

Resim 2. Sağ ayağın manyetik rezonans görüntüleme incelemesinde talonavikülar (ok), naviküloküneiform (ok), tarsometatarsal eklemler ile kalkaneoküboid ile 5. metatarsal eklem komşuluğunda periartiküler kemik iliği ödemi ve yumuşak doku koleksiyonları gösteren T1 ağılıklı sagittal ve aksiyel görüntülerde hipointens ve T2 ağırlıklı sagittal görüntülerde sinyal artışı gösteren alanlar izleniyor. Kontrastlı serilerde periartiküler yumuşak dokuda ve subkortikal eklem yüzeylerinde zayıf kontrast tutulumları görülüyor

\section{Tartışma}

$\mathrm{CN}$ en sık diabetes mellitus ile birlikteliği bildirilmiştir. $\mathrm{CN}$ diyabetin tipi, şiddeti ve insülin bağımlıı̆ı ile ilişkisi gösterilememiştir (8). En sık görülme yaşı 5 ve 6. dekatlardır (9). Olguların büyük çoğunluğunda diyabet süresi 10 yıl ve üzerindedir (10). Bilateral tutulum \%9-17,1 oranında bildirilmiştir $(11,12)$. Obez diyabetiklerde CN gelişim riskinin arttığı bildirilmektedir (13). Hastamız obez ve diyabet süresi 13 yıl olan CN'nin tek taraflı alt ekstremite de izlendiği bir hastaydı. CN'nin etiyopatogenezi net olmamakla birlikte; oluşumunda iki temel teori üzerinde durulmuştur. Birincisi nörotravmatik teoridir. Duyarlılığı azalmış eklemde meydana gelen fark edilmemiş tekrarlayan mikro travma nedeniyle pediatrikler kırıklar ve dislokasyonlar meydana gelmektedir. İkincisi ise nörovasküler teoridir. Otonomik nöropati gelişimi nedeniyle sempatik denervasyona bağlı kemiğin kan akımında artış meydana gelmekte, kemik yapım ve yıkım dengesi ile osteoligamantoz mimari bozulmaktadır (2). CN'nin etiyopatogenezinde proenflamatuvar sitokinlerin rolü de araştırılmıştır. Bu hastalarda nükleer faktör kappa B 
ligand reseptör aktivatörü (RANKL) ve enflamatuvar sitokin yapımının kontrolsüz artışının lokal osteolize neden olduğu bildirilmiştir (9). Witzke ve ark. (10) CN gelişen hastalarda ileri glikasyon son ürünleri için reseptörler (RAGE) düzeylerini yüksek tespit etmişlerdir. RAGE, RANKL aktivasyonunu artıran ve osteoklastogenezi indükleyen bir moleküldür.

CN'de en sık ayağın orta ayak bölümü etkilenmektedir. Kliniğinde akut dönemde etkilenen bölgede şişlik kızarıklık ve ısı artışı izlenmektedir. Periferal nabızlar genellikle korunmuştur. Ayak Isısı önemli bir göstergedir. Akut dönemde etkilenmiş ayak ile diğer taraf arasında 2 derece ve üzerinde fark bulunur. Isı farkının 2 derecenin altına inmesi akut dönemin sona erdiğini gösterir. Hastalığın seyrinde izlenen erozyon, fraktür, subluksasyon ve dislokasyonlar nedeniyle longitudinal arkın kollapsı gelişerek, rocker botom ayak deformitesi ve ayak bileğinde instabilite görülebilir (2). Eichenholtz klasifikasyonuna göre hastalık 3 evrede değerlendirilir. Evre 1 başlangıç evresidir. Genelde 2-6 hafta sürer. Evre 2'de şişlik ve ısı artışı azalır. Enflamasyon yerleşir, yapısal bozukluğa yol açmayan eklem subluksasyonu ve disklokasyon mevcuttur. Evre 3 enflamasyonun kaybolduğu deformasyonun meydana geldiği evredir. ikinci ve 3. evre 18-24 ay sürer (14). Hastamızda subluksasyonların ve deformitelerin izlenmesi, her iki ayak arasında ısı farkının olmayışı ve eritem izlenmemesi nedeniyle kronik evre 3 olarak değerlendirilmiştir.

Bu hastalarda ayııııı tanının dikkatli bir biçimde yapılması önem arz eder. Ayııııı tanı enfeksiyon, sellülit, osteomiyelit, gut, derin ven trombozu, venöz yetersizlik, lenfödem, artrit ile yapılmalıdır. Özellikle enfeksiyonlar ve vasküler patolojiler diyabet seyrinde sık görüldüklerinden en sık tanı karmaşasına neden olan gruplardır (5). Hastamızın yakınmaları mevcut venöz yetersizliğe bağlanmış ve ek bir inceleme yapılmamışıır. Bu da tanıda gecikmeye neden olmuştur. Diyabetik hastalarda birden fazla klinik durumun bir arada görülebileceği unutulmamalıdır.

Charcot nöropatisinin özellikle 1. evresinde osteomiyelitten ayırımı oldukça zordur. MRG, kortikal bozulma olsun ya da olmasın kemik iliğinin T1 ağırlıklı görüntülerde düşük sinyal ve T2 ağırlıklı görüntülerde yüksek sinyal göstermesi osteomiyelit için oldukça karakteristiktir. CN primer olarak periartiküler yerleşimli iken, osteomiyelit özellikle komşuluğundaki deri ülserleri ve sinüs yollarındaki enfeksiyonun yaylımı ile gelişir. $\mathrm{CN}$ yaygın olarak tarsometatarsal ve metatarsofalangeal eklemler gibi birçok eklemi etkilerken, osteomiyelit kalkaneus, malleolus ve falankslarda lokalize tutulumlar gösterir. Kronik CN tanısı almış bir hastanın MRG görüntülerinde kemik iliği T2 sinyalinde ve kontrastlanmasında belirgin artış, ilerleyici kemik rezorbsiyonu, subkutanöz yağ dokusunda sinyal kaybı, eklem komşuluğundaki yumuşak dokudaki sıvı koleksiyonlarıın varlığı ve sinüs traktı ve ülser gelişimi osteomiyelitin süperpoze olduğunun göstergeleridir (15). Artrit ile ayıııı tanısında akut faz yanıtının olmaması, sinovit ve eklem içi efüzyonun olmaması ile yapılabilir. Vasküler patolojilerde Doppler ultrasonografi ayırıcı tanıda faydalıdır (2). Hastamızda kronik dönem CN saptanmışıı. Bu nedenle enfeksiyonu düşündüren şişlik kızarıklı Isı artışı izlenmedi. Kronik şişliğe neden olabilecek venöz yetersizlik, kronik artrit ve lenf ödem gibi patolojilerle ayıııı tanı yapılmıştır. Hastanın venöz yetersizliğinin de saptanmış olması $\mathrm{CN}$ tanııının konulmasında gecikmeye neden olmuştur. Bazen iki ayrı klinik antitenin bir arada da bulunabileceği göz önünde bulundurulmalıdır.

Tanıda en sık başvurulan tetkik X-ray'dir. Akut dönemde $X$-ray görüntülemede yumuşak doku şişliği bazen gözlenmekle birlikte belirgin patoloji görülmez. Illerleyen dönemlerde X-ray görüntülemede hastalığa özgü $5 D$ bulgusu gözlenir. $5 D$ bulgusu eklem distansiyonu, kemik debris, kartilaj destrüksiyonu, disorganizasyon (ya da dislokasyon ya da deformite) ve artmış kemik dansitesi olarak tanımlanır. Bilgisayarlı tomografi eklemlerin ince kesit görüntülenmesi ve üç boyutlu sunum imkanı sağlamasıyla cerrahiyi planlamada yararlı olabilir. MRG özellikle osteomiyelit ile ayııııı tanıda oldukça değerlidir. Metal implant nedeniyle MRG yapılamayan hastalarda erken dönem $\mathrm{CN}$ ile osteomiyelit ayırımında pozitron emisyon tomografi kullanılabilir. Kemik sintigrafisi CN tanısı koymada yeterli değildir (2). Hastamızda tanıda X-ray ve MRG kullanılmıştır.

CN'de ayakta etkilenen bölge Brodsky's sınıflamasına göre değerlendirilmektedir. Tutulum bölgesine göre deformiteler ve hastalık seyri farklıdır. Tip 1'de tarsometatarsal ve naviküloküneiform eklem tutulumu olur. Hastaların \%65-70'inde gözlenen en sik formdur. Tip 2'de subtalar, talanaviküler ve kalkaneoküboid eklemler etkilenir. Olguların \%20-25'ini oluşturur. Tip 3a'da ayak bileği eklemi tutulurken, Tip 3b'de ise kalkaneal tuberosit etkilenmektedir. Tip $1 \mathrm{CN}^{\prime}$ de orta ayakta valgus deformitesi ve roccer bottom deformitesi izlenir. Deformiteler genelde hipertrofiktir. Tip 2'de eroziv değişiklikler daha belirgindir. Instabilite daha sıklıkla görülür. Tip 1'e göre daha fazla immobilizasyon gereklidir. Tip 3a'da ayakta varus valgus deformitesi sık görülür. İnstabilite ve ossöz çıkıntılar sık izlenir. Tip $3 b^{\prime}$ de ise kalkaneal tuberosit fraktürleri ve büyük kemik fragmanları izlenir (16). Hastamızda tip 1 ve $2 \mathrm{CN}^{\prime}$ nin tutulum bölgeleri ve bulguları birlikte izlenmiştir.

Tedavide akut dönemde yüklenmeden kaçınma önerilmektedir. Bu amaçla tam temas alçılamanın 8-12 hafta süre ile kullanılması önerilir. Akut faz yatıştı̆ında ayak ayak bileği ortezi, charcot ortotik wolker ya da ölçülü ayakkabı kullanımı önerilir. Kronik dönemde çıkarılabilir wolker ve braceler ile özel ayakkabıya geçilir. Parsiyel yük verme önerilir. Aşıı mobilizasyondan relaps ve hastalığın progresyonu açıından kaçınılması önerilir (17). CN'nin medikal tedavisinde bifosfonatlar (alendronat, zoledronik asit) ve kalsitonin denenmiş fakat etkisi tartışmalıdır (2). Charcot artropatisinde ameliyat endikasyonları kısıtıdır. Cihaz ile tedavi edilemeyen fiske deformite ve belirgin deformite varlığı, cast immobilizasyonu ile kontrol altına alınamayan, rekurren ülserasyon ve enfeksiyonlarda cerrahi düşünülebilir (18). Diyabete bağlı periferik arter hastalı̆̆ı, doku iyileşmesinin yavaş olması sebebi ile cerrahi tedavi sonrası enfeksiyon, nonunion, malünyon, stres fraktürü, fiksasyon yetersizliği, metalin yumuşak dokuyu irritasyonu, implantın kırıması ya da gevşemesi gibi komplikasyonlar görülebilir (18-20). Eksostektomi, artrodesis ve amputasyon uygulanabilecek cerrahi seçeneklerdir (2). 
Hastamızda cerrahi düşünülmedi. Çıkarılabilir brace ve wolker verilerek takibe alındı.

Diyabetik hastalarda polinöropati varlığında ayakta meydana gelen şişliklerde CN ayırıcı tanıda mutlaka düşünülmelidir. Uygun takip ve tedavi morbiditeyi azaltmada önemlidir.

\section{Etik}

Hasta Onayı: Hastadan bilgilendirilmiş onam formu alınmıştır. Hakem Değerlendirmesi: Editörler kurulu tarafından değerlendirilmiş̧tir.

\section{Yazarlık Katkıları}

Cerrahi ve Medikal Uygulama: R.T., Konsept: R.T., Dizayn: R.T. Veri Toplama veya İşleme: R.T., T.Ö., Analiz veya Yorumlama: R.T., T.Ö., T.A., Literatür Arama: R.T., T.A., Yazan: R.T.

Çıkar Çatışması: Yazarlar bu makale ile ilgili olarak herhangi bir çıkar çatışması bildirmemiştir.

Finansal Destek: Çalışmamız için hiçbir kurum ya da kişiden finansal destek alınmamıştır.

\section{Kaynaklar}

1. Eschler A, Gradl G, Wussow A, Mittlmeier T. Late corrective arthrodesis in nonplantigrade diabetic charcot midfoot disease is associated with high complication and reoperation rates. J Diabetes Res 2015;2015:246792.

2. Madan SS, Pai DR. Charcot neuroarthropathy of the foot and ankle. Orthop Surg 2013;5:86-93.

3. Viens NA, Watters TS, Vinson EN, Brigman BE. Case report: Neuropathic arthropathy of the hip as a sequela of undiagnosed tertiary syphilis. Clin Orthop Relat Res 2010:468:3126-31.

4. Charcot JM. Sur quelques arthropathies qui paraissent öependre d'une lesion du cerveau ou de la moelle epiniere. Arch Physio Norm Pathol 1868:1:161-78.

5. Madan SS, Pai DR. Charcot neuroarthropathy of the foot and ankle. Orthop Surg 2013;5:86-93.

6. Wukich DK, Sung W. Charcot arthropathy of the foot and ankle: modern concepts and management review. J Diabetes Complications 2009;23:409-26.
7. Wukich DK, Sung W, Wipf SA, Armstrong DG. The consequences ofcomplacency: managing the effects of unrecognized Charcot feet. Diabet Med 2011;28:195-8.

8. Stuck RM, Sohn MW, Budiman-Mak E, Lee TA, Weiss KB. Charcotarthropathy risk elevation in the obese diabetic population. Am J Med 2008;121:1008-14.

9. Rogers LC, Frykberg RG, Armstrong DG, Boulton AJ, Edmonds $\mathrm{M}$, Van $\mathrm{GH}$, et al. The Charcot foot in diabetes. Diabetes Care 2011:34:2123-9.

10. Witzke KA, Vinik Al, Grant LM, Grant WP, Parson HK, Pittenger GL, et al. Loss of RAGE defense: a cause of Charcot neuroarthropathy? Diabetes Care 2011;34:1617-21.

11. Armstrong DG, Todd WF, Lavery LA, Harkless LB, Bushman TR. The natural history of acute Charcot's arthropathy in a diabetic foot specialty clinic. J Am Podiatr Med Assoc 1997:87:272-8.

12. Gonzalez Fernandez ML, Morales Lozano R, Martinez Rincon C, Martinez Hernandez D. Personalized orthoses as a good treatment option for Charcot neuro-osteoarthropathy of the foot. J Am Podiatr Med Assoc 2014;104:375-82.

13. Stuck RM, Sohn MW, Budiman-Mak E, Lee TA, Weiss KB. Charcotarthropathy risk elevation in the obese diabetic population. Am J Med 2008;121:1008-14

14. Eichenholtz SN. Charcot joints. Springfietd, IL: Charles C Thomas: 1966.

15. Ergen FB, Sanverdi SE, Oznur A. Charcot foot in diabetes and an update on imaging. Diabet Foot Ankle 2013:4.

16. Brodsky JW. The diabetic foot. In: Coughlin MJ. Mann RA. editors. Surgery oflhc foot and ankle. Vol 2. 7th ed, St, Louis: Mosby: 1999. p. 895-969.

17. Güven MF, Karabiber A, Kaynak G, Oğüt T. Conservative and surgical treatment of the chronic Charcot foot and ankle. Diabet Foot Ankle 2013;4.

18. Koller A, Hafkemeyer U, Fiedler R, Wetz HH. Reconstructive foot surgery in cases of diabetic-neuropathic osteoarthropathy. Orthopade 2004:33:983-91.

19. Pinzur MS, Sostak J. Surgical stabilization of nonplantigrade Charcot arthropathy of themidfoot. Am J Orthop (Belle Mead NJ) 2007;36:361-5.

20. Eschler A, Gradl G, Wussow A, Mittlmeier T. Late corrective arthrodesis in nonplantigrade diabetic charcot midfoot disease is associated with high complication and reoperation rates. J Diabetes Res 2015;2015:246792. 